\title{
RADIOLOGICAL PREDICTORS OF MORTALITY IN PATIENTS WITH PRIMARY SPONTANEOUS INTRACEREBRAL HAEMORRHAGE
}

\author{
Krishnakumar P1, Biju Bhadran², G. Harrison ${ }^{3}$, Aravind K. $R^{4}$
}

${ }_{1}^{1}$ Assistant Professor, Department of Neurosurgery, Government TD Medical College, Alappuzha, Kerala.

2Professor, Department of Neurosurgery, Government TD Medical College, Alappuzha, Kerala.

${ }^{3}$ Assistant Professor, Department of Neurosurgery, Government TD Medical College, Alappuzha, Kerala. ${ }^{4}$ Senior Resident, Department of Neurosurgery, Government TD Medical College, Alappuzha, Kerala.

ABSTRACT
BACKGROUND
Primary spontaneous intracerebral haematoma (ICH) is a deadly form of stroke with very high mortality and morbidity. Outcome
prediction is mandatory for optimisation of therapeutic efforts. The objective of our prospective study is to identify reliable
radiological predictors of mortality from a plain CT study of brain.

\section{MATERIALS AND METHODS}

We prospectively collected clinical and radiological data from 112 patients with primary ICH. Key measurements were taken from the plain CT scan of brain at admission to collect the radiological parameters. Bivariate analysis of clinical and radiological predictors of poor outcome were undertaken using unadjusted logistic regression analysis. Those radiological variables found to have statistical significance on bivariate analysis were analysed using multivariate logistic regression model. The regression model was validated using ROC (Receiver Operating Characteristic) curve.

\section{RESULTS}

The mortality in our series was $28.6 \%(\mathrm{~N}=32)$. Radiological factors associated with poor outcome on bivariate analysis were volume of haemorrhage, Midline Shift (MLS), Intraventricular Haemorrhage (IVH) and hydrocephalus. On multivariate analysis IVH $(\mathrm{P}=.007)$, MLS (.008) and volume of haemorrhage $(\mathrm{P}=.029)$ were significantly associated with poor outcome. Using ROC curve, we had a cut-off volume of $42.5 \mathrm{~cm}^{3}$ with an optimum sensitivity of $81.2 \%$ and specificity of $90 \%$.

\section{CONCLUSION}

Plain CT study of brain obtained within 24 hours of the ictus can be reliably used for predicting the prognosis of subjects with primary supratentorial ICH.

\section{KEYWORDS}

Intracerebral Haematoma, Radiological Predictors, Intraventricular Haemorrhage, Stroke.

HOW TO CITE THIS ARTICLE: Krishnakumar P, Bhadran B, Harrison G, et al. Radiological predictors of mortality in patients with primary spontaneous intracerebral haemorrhage. J. Evolution Med. Dent. Sci. 2018;7(18):2192-2196, DOI: $10.14260 /$ jemds/2018/493

\section{BACKGROUND}

Primary spontaneous intracerebral haemorrhage (ICH) is the most disabling form of stroke with an overall mortality rate approaching $40 \%{ }^{(1,2,3)}$ This accounts to $4-14 \%$ of all strokes with $22 \%$ to $62 \%$ of deaths taking place in the first 30 days. $(4,5,6)$ The incidence of ICH increases with age.(7) Unfortunately, the best treatment modality for this neurological emergency is yet to be defined.(8,9,10) An early and accurate outcome prediction model is crucial for decision making and prognostication. The burden of stroke occurrence is more in developing nations. Several clinical, radiological and biochemical prognostic variables have been proposed for the purpose of prognostication, $(11,12)$ but each variable appears to impact the outcome in a different way. Plain CT scan remains the standard diagnostic test for ICH. In this

'Financial or Other Competing Interest': None.

Submission 17-03-2018, Peer Review 12-04-2018,

Acceptance 18-04-2018, Published 30-04-2018.

Corresponding Author:

Krishnakumar $P$

Assistant Professor,

Department of Neurosurgery,

Government TD Medical College, Alappuzha, Kerala.

E-mail: drpkrishnan77@gmail.com

DOI: $10.14260 /$ jemds $/ 2018 / 493$

\section{(c) $(1) \$$}

study, we examine whether the radiological parameters obtained from a plain CT scan of brain can be used for prognostication purpose in primary spontaneous ICH.

\section{MATERIALS AND METHODS}

The study was approved by the Institutional Ethics Committee. This was a prospective observational study done in Government TD Medical College, Alappuzha, which is a tertiary level referral hospital in southern part of India. All consecutive patients admitted with primary spontaneous supratentorial ICH presented to the emergency section of the hospital between May 2017 and December 2017 were recruited for the study. For the purpose of the study primary intracerebral haematoma was defined as spontaneous leakage of blood into the brain parenchyma, documented by a plain CT study of the brain. Secondary ICH due to trauma, rupture of arteriovenous malformations, aneurysmal bleeds, patients above 80 years of age and those presenting after 24 hrs. of ictus were excluded from the study. Informed consent was taken from the patients or their attendants. Patient's attendants were interviewed to take a detailed clinical history regarding the onset, progression, headache, seizures and chronology of neurological worsening since ictus. History of hypertension, diabetes mellitus, alcoholism and smoking 
were recorded. The Glasgow Coma Scale (GCS) score of the patient was noted on admission.

\section{Radiological Analysis}

All patients underwent a plain CT scan of the brain on admission itself. Image analysis was done to assess the following parameters-

1. Volume of haematoma.

2. Midline shift (MLS).

3. Intraventricular haemorrhage (IVH).

4. Hydrocephalus.

5. Side of haematoma (Left/Right).

The volume of haematoma was measured by using the formula $\mathrm{ABC} / 2$, where $\mathrm{A}$ is the greatest haemorrhage diameter by CT, $\mathrm{B}$ is the diameter 90 degrees to $\mathrm{A}$ and $\mathrm{C}$ is the approximate number of CT slice with haemorrhage multiplied by slice thickness.(13) The primary endpoint was either death in hospital or live follow-up at 30 days.

\section{Statistical Analysis}

All data were analysed using SPSS software version 16.0 (SPSS Inc., Chicago, Illinois, USA). Descriptive statistics were presented as means with standard deviation for continuous variables and as percentages for categorical variables. Bivariate analyses of clinical and radiological predictors of death were undertaken using logistic regression. Those radiological variables having significance were analysed using a multivariate logistic regression model. Model discrimination was validated using AUC (Area Under ROC). A $P$ value less than .05 was considered significant.

\begin{tabular}{|c|c|c|c|}
\hline Variable & P value & $\begin{array}{c}\text { OR } \\
\text { (Odds Ratio) } \\
\end{array}$ & $95 \% \mathrm{CI}^{\dagger}$ \\
\hline \multicolumn{4}{|l|}{$\begin{array}{c}\text { Demographics and } \\
\text { Risk Factors }\end{array}$} \\
\hline $\begin{array}{l}\text { Age ( } \geq 65 \text { years }) \\
\text { Sex }\end{array}$ & .022 & 2.719 & $1.157-6.391$ \\
\hline $\begin{array}{l}\text { Sex (Male vs. } \\
\text { Female) }\end{array}$ & .273 & 0.615 & $0.258-1.466$ \\
\hline Hypertension & .011 & 3.397 & $1.319-8.748$ \\
\hline \multirow{3}{*}{$\begin{array}{c}\text { Diabetes Mellitus } \\
\text { Alcohol } \\
\text { Smoking }\end{array}$} & .294 & 1.756 & $0.613-5.031$ \\
\hline & .750 & 1.189 & $0.409-3.461$ \\
\hline & .860 & 0.962 & $0.621-1.488$ \\
\hline $\begin{array}{l}\text { Clinical Variable } \\
\text { GCS }(\leq 8 \text { vs. }>8)\end{array}$ & $<.001$ & 0.03 & 0.009-0.098 \\
\hline \multicolumn{4}{|l|}{$\begin{array}{c}\text { Radiological } \\
\text { Variable } \\
\text { Volume of } \\
\text { haematoma }\end{array}$} \\
\hline $\begin{array}{c}\leq 30 \mathrm{~mL} \text { vs. }>30 \mathrm{~mL} \\
\text { Midline shift }(\mathrm{MLS}) \\
\leq 6 \mathrm{~mm} \text { vs }>6 \mathrm{~mm} \\
\mathrm{IVH} \ddagger\end{array}$ & $<.001$ & 17.72 & $3.614-86.947$ \\
\hline \multirow{2}{*}{$\begin{array}{l}\text { Present vs. Absent } \\
\text { Hydrocephalus }\end{array}$} & $<.001$ & 30.60 & $9.842-95.158$ \\
\hline & $<.001$ & 10.371 & $4.035-26.660$ \\
\hline $\begin{array}{c}\text { Present vs. Absent } \\
\text { Side } \\
\text { Left vs. Right }\end{array}$ & .121 & 1.929 & $0.841-4.420$ \\
\hline
\end{tabular}

*Dependent variable: Mortality $+95 \%, \quad$ CI: 95 percent Confidence Interval. $¥ \mathrm{IVH}$ : Intraventricular haemorrhage.

\section{RESULTS}

Out of the 138 admissions, only 112 subjects were finally recruited for the study after making the necessary exclusions. The mortality rate was $28.6 \%(\mathrm{~N}=32)$. The mean age was 63.20 years (Median 64 years, range 33 to 79 years). There were a total of $68(60.71 \%)$ males and $44(39.2 \%)$ females. Major clinical presentation was headache and altered sensorium in 60 patients (53.57\%), loss of consciousness in 35 patients $(31.25 \%)$ and headache alone in 17 patients (15.17\%). The most common risk factor in our study was hypertension 66 (58.9\%) followed by smoking 28 (25\%), alcohol intake $19(17 \%)$ and diabetes mellitus $18(16 \%)$. The mean GCS was 11 with a median of 13 . The GCS was significantly low for patients who expired (6 vs. 14, $\mathrm{p}=.001$ ). The mean hospital stay was 11 days with the survivors having significant prolonged stay (mean 13 vs. $4, \mathrm{p}<.001$ ). More than half of the deaths occurred in the first 48 hours (53.12\%, N= 17). Only 14 patients $(12.5 \%)$ underwent a surgical procedure with decompressive craniotomy and evacuation in 11 (9.8\%) and external ventricular drainage alone in $3(2.6 \%)$ patients. Overall, there was no significant difference in mortality between the conservative and surgical group $(\mathrm{p}=0.119)$.

All patients underwent a plain CT brain as part of their management. The mean haematoma volume was $43.4 \pm 9.6$ $\mathrm{mL}$ (range $4-230 \mathrm{~mL}$ ). The average midline shift for the whole series was $1.9 \mathrm{~mm}$ (range 0 - 12). Intraventricular haemorrhage was present in $34.8 \% \quad(\mathrm{~N}=39)$ and hydrocephalus in $32 \%(\mathrm{~N}=36)$ of the individuals. On bivariate analysis significant radiological predictors of inhospital mortality were haematoma volume, midline shift, IVH and hydrocephalus (Table 1). There was good correlation between haematoma volume and MLS with GCS. (Pearson correlation -0.50 and -0.49 respectively, $\mathrm{p}<.001$ for both). Those with IVH and hydrocephalus had a significant low GCS $(\mathrm{p}<.001)$. For multivariate logistic regression analysis, collinear variables were eliminated in the model. After multivariate analysis MLS, presence or absence of IVH and volume of ICH were significant predictors of mortality (Table 2 ). The regression analysis showed a good validation with an area under ROC curve (AUC) of 0.867 (Fig. 1). Cross tabulation of variables with outcome is given in Table 3 .

\begin{tabular}{|c|c|c|c|}
\hline $\begin{array}{c}\text { Radiological } \\
\text { Variable }\end{array}$ & P value & Odds Ratio & 95\% CI \\
\hline MLS > 6 mm & .023 & 20.106 & $1.526-265.24$ \\
\hline $\begin{array}{c}\text { Volume of } \\
\text { haematoma > 30 mL }\end{array}$ & $<.001$ & 16.85 & $4.13-68.61$ \\
\hline IVH & .007 & 9.067 & $1.840-44.69$ \\
\hline Hydrocephalus & .266 & 2.517 & $0.494-12.821$ \\
\hline Side & .865 & 0.880 & $0.202-3.839$ \\
\hline \multicolumn{3}{|c|}{ Table 2. Multivariate Logistic Regression of } \\
Radiological Variables \\
\hline
\end{tabular}

Dependent variable: Mortality, MLS, Volume of haematoma and IVH are significant predictors of outcome, $\mathrm{p}<.05$. 


\begin{tabular}{|c|c|c|c|}
\hline \multirow{2}{*}{\multicolumn{2}{|c|}{ Variable }} & \multicolumn{2}{|c|}{ Outcome } \\
\hline & & Dead (n= 32) & Alive $(n=80)$ \\
\hline \multicolumn{2}{|c|}{ Age } & $66.75(2.062)^{*}$ & $61.787(2.079)$ \\
\hline \multirow{2}{*}{ Sex } & Male & $68.8 \%$ & $57.5 \%$ \\
\hline & Female & $31.2 \%$ & $42.5 \%$ \\
\hline \multicolumn{2}{|c|}{ Hypertension } & $78.1 \%$ & $51.2 \%$ \\
\hline \multicolumn{2}{|c|}{ Diabetes Mellitus } & $21.9 \%$ & $13.8 \%$ \\
\hline \multicolumn{2}{|c|}{ Alcohol } & $18.8 \%$ & $16.2 \%$ \\
\hline \multicolumn{2}{|c|}{ Smoking } & $31.2 \%$ & $22.5 \%$ \\
\hline \multicolumn{2}{|c|}{ GCS } & $6(3-14)^{\dagger}$ & $14(6-15)$ \\
\hline \multicolumn{2}{|c|}{ Volume (mL) } & 92.96 & 23.6 \\
\hline \multicolumn{2}{|c|}{ MLS (mm) } & 4.71 & 0.81 \\
\hline \multicolumn{2}{|c|}{ IVH } & $84.4 \%$ & $15 \%$ \\
\hline \multicolumn{2}{|c|}{ Hydrocephalus } & $68.8 \%$ & $17.5 \%$ \\
\hline \multirow{2}{*}{ Side } & Right & $43.8 \%$ & $60 \%$ \\
\hline & Left & $56.2 \%$ & $40 \%$ \\
\hline
\end{tabular}

*Age is given as Mean (SD). † GCS is given as Median (range).

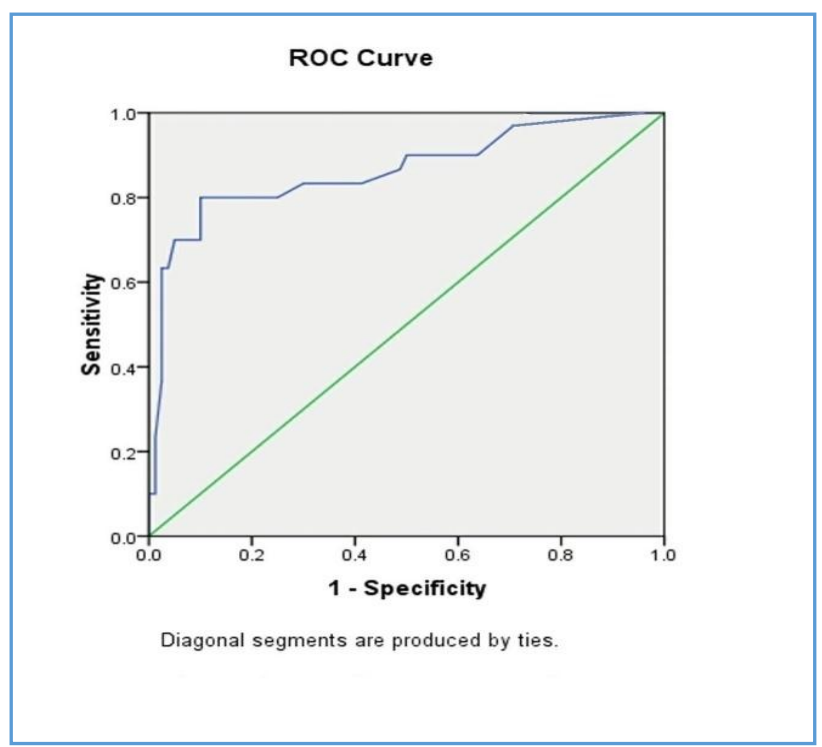

\section{Figure 1. ROC Curve depicting AUC of Logistic Regression Model. AUC: 0.867}

\section{DISCUSSION}

In this study, we demonstrated that the following radiological parameters- 1) MLS, 2) IVH and 3) Volume of haemorrhage can be used to predict the prognosis of patients with primary spontaneous supratentorial intracerebral haemorrhage. Since primary intracerebral haemorrhage is an entity which accounts for $15 \%$ to $20 \%$ of all strokes and have a high mortality rate with poor consensus regarding management, the prognostication of such patients assumes paramount importance.(14) Since infratentorial haemorrhages constitute a separate entity with respect to treatment and natural history, unlike many other studies we did not include them in our study. Our mortality rate of $28.6 \%$ was similar to many other series.(15) Many studies combine clinical and radiological variables together in their model. This would lead to the problem of collinearity with each other and necessary elimination will have to be carried out on grounds of clinical practicality. This collinearity is due to the fact that the radiological variables are an effect of the clinical condition rather than the cause.
Al Mufti et al(16) conducted a literature review on various radiological factors, which affected the outcome. Haematoma location, volume, expansion, spot sign, swirl sign, perihaematomal oedema, IVH and hydrocephalus were the most studied radiological predictors. Haematoma volume and IVH has been found to be independent prognostic factor in several studies.(17,18,19) For a given location in the brain, the volume of haematoma was the strongest predictor of 30-day mortality. In our study, volume was a significant predictor of poor outcome $(\mathrm{P}=.029)$. The mean haematoma volume was 92.96 $\mathrm{cm}^{3}$ in patients with poor outcome when compared to 23.6 $\mathrm{cm}^{3}$ in those who had recovery. In a study of 30 days mortality based on ICH volume, Broderick et al(20) have reported $93 \%$ mortality for deep and $71 \%$ mortality for lobar haemorrhages more than $60 \mathrm{~cm}^{3}$. Flemming et al(21) identified $40 \mathrm{~mL}$ as a critical volume predicting poor outcome. Using ROC curve, we had a cut-off value at $42.5 \mathrm{~mL}$ with optimum sensitivity and specificity in our dataset (sensitivity $81.2 \%$, specificity $90 \%$ ). Many studies have observed a good cut-off at $30 \mathrm{~mL}$. Haematoma expansion which is defined as an increase in volume by more than $33 \%^{(22)}$ has been associated with a worse outcome. ${ }^{(22,23)}$ Lateral shift of midline structures which occur due to the mass effect of the haematoma and the oedema associated with it was a significant prognostic variable in our study $(\mathrm{P}=.008)$. There was good correlation between haematoma volume and MLS in our study (Pearson's correlation $0.706, \mathrm{P}<.05$ ). Though associated with poor outcome, MLS has not attained statistical significance in several studies.(24) This is due to the fact that many studies include infratentorial haemorrhages also, where MLs may be absent. Fogelholm et al, however, in their study has demonstrated a significant relationship between MLS and outcome.

In our study, IVH has been found to be the strongest radiological predictor $(\mathrm{P}=.007)$ with an $\mathrm{OR}$ of 8.43 . Across several studies, IVH is consistently associated with a worse outcome. IVH was present in $84.4 \%$ of subjects with poor outcome when compared to $15 \%$ in those who had good recovery. A study by Leira et al(25) showed a 2.6 times chance of neurological deterioration following IVH. The blood collected in the ventricle can obstruct the ventricular system and produce hydrocephalus. Blood in the ventricle also make the patient seizure prone. Both these factors contribute to the neurological deterioration. Diringer et al(26) in their study found that apart from other variables, pineal body shift and hydrocephalus were significant predictors of mortality. In their multivariate analysis, the $P$ value was reduced to 0.1 to fit other variables into the model. In our study, hydrocephalus did not attain clinical significance $(\mathrm{P}=.123)$.

The damage to brain in ICH occurs in three phases. (27) The first phase consists of arterial rupture and bleed, second phase is of haematoma expansion and third phase is due to oedema. About $30 \%$ of the patients exhibit haematoma growth in first six hours post ictus, which is evident from the high mortality documented in the first 24 hours in several studies. Enlargement seldom occurs after 24 hours.(28) In our study also, the $53.12 \%$ of the mortality occurred in the first 48 hours. So by the end of first 48 hours, major damage to the nervous tissue had already occurred. This is the reason why craniotomy after 24 hours does not have an advantage over aggressive medical management in treatment of deep seated haematoma as laid down in STICH trial. In our series also, 
surgical group did not have a significant advantage $(\mathrm{P}=$ 0.119).

Side was not a significant factor affecting mortality in our study. Lee et al(29) have found that putaminal haemorrhage occurred mainly on the side of dominant A1. Spot sign, blend sign and swirl sign are among the other major radiological predictors of mortality studied in different series. The presence of spot sign, active extravasation of contrast into the haematoma was considered an indicator of active haemorrhage and was associated with high mortality in many studies.(30) A spot sign scoring system has been developed by Delgado Almandoz et al,(31) which reliably and independently predicted mortality and poor outcome among survivors. This needs a contrast CT however. Another radiological sign has been swirl sign. This sign described in epidural haematoma with low attenuation and irregular density has been shown in intracerebral haemorrhages also, which if present is an independent predictor of death at one month.(32) In their study, swirl sign was present only in $30 \%$ of the study population. Blend sign has been described by Li $Q$ et al.(33) This is defined as- (1) Blending of relatively hypoattenuating area with adjacent hyperattenuating region within a haematoma; (2) There is a well-defined margin between the hypoattenuating area and adjacent hyperattenuating region that is easily recognised by the naked eye; (3) The haematoma should have at least a 18 Hounsfield unit difference between the 2 density regions; (4) The relatively hypoattenuating area was not encapsulated by the hyperattenuating region. They have reported that it has got $95.5 \%$ specificity for predicting haematoma growth. This sign was however observed only in $16.9 \%$ of patients with ICH. Black hole sign has been described by Qi Li et al.(34) This was a hypoattenuating area encapsulated within a hyperattenuating haematoma. The relatively hypoattenuating area should have clearly defined borders. The two regions must have a 28 Hounsfield units (HU) difference between them. This was present in $14.6 \%$ of patients and was specific (94.1\%) for predicting haematoma growth. Of the blend sign, spot sign and black hole sign, the spot sign was the most reliable outcome predictor.(35) Barras CD et al(36) have reported that heterogeneity of density within the haematoma independently predicted poor outcome. These signs however are not present in all patients and hence cannot be applied to all patients with uniformity.

\section{CONCLUSION}

Plain CT study of brain taken in first 24 hours of ictus is has a significant value not only in diagnosing but also in predicting the outcome in patients with primary spontaneous ICH. Volume of haemorrhage, MLS and IVH were statistically significant predictors. The relative small number of patients and its single institutional nature were major limitations of our study. Multi-institutional studies with larger number of subjects are required to further validate the radiological prognostic variables.

\section{REFERENCES}

[1] Dennis MS. Outcome after brain haemorrhage. Cerebrovasc Dis 2003;16 (Suppl 1):9-13.

[2] Godoy DA, Piñero G, Di Napoli M. Predicting mortality in spontaneous intra-cerebral haemorrhage. Can modification to original score improve the prediction? Stroke 2006;37(4):1038-44.

[3] Flaherty ML, Haverbusch M, Sekar P, et al. Long-term mortality after intra-cerebral haemorrhage. Neurology 2006;66(8):1182-6.

[4] Bilbao G, Garibi J, Pomposo I, et al. A prospective study of a series of 356 patients with supratentorial spontaneous intra-cerebral haematomas treated in a Neurosurgical Department. Acta Neurochir (Wien) 2005;147(8):823-9.

[5] Bhatia R, Singh H, Singh S, et al. A prospective study of in-hospital mortality and discharge outcome in spontaneous intra-cerebral haemorrhage. Neurol India 2013;61(3):244-8.

[6] Fogelholm R, Murros K, Rissanen A, et al. Long term survival after primary intra-cerebral haemorrhage: a retrospective population based study. J Neurol Neurosurg Psychiatry 2005;76(11):1534-8.

[7] Togha M, Bakhtavar K. Factors associated with inhospital mortality following intra-cerebral haemorrhage: a three-year study in Tehran, Iran. BMC Neurology 2004;4:9.

[8] McKissock W, Richardson A, Taylor J. Primary intracerebral haemorrhage: a controlled trial of surgical and conservative treatment in 180 unselected cases. Lancet 1961;2:221-6.

[9] Batjer HH, Reisch JS, Allen BC, et al. Failure of surgery to improve outcome in hypertensive putaminal haemorrhage. A prospective randomized trial. Arch Neurol 1990;47(10):1103-6.

[10] Auer LM, Deinsberger W, Niederkorn K, et al. Endoscopic surgery versus medical treatment for spontaneous intra-cerebral hematoma: a randomized study. J Neurosurg 1989;70(4):530-5.

[11] Hemphill JC, Bonovich DC, Besmertis L, et al. The ICH score: a simple, reliable grading scale for intracerebral haemorrhage. Stroke 2001;32(4):891-7.

[12] Nilsson OG, Lindgren A, Brandt L, et al. Prediction of death in patients with primary intra-cerebral haemorrhage: a prospective study of a defined population. J Neurosurg 2002;97(3):531-6.

[13] Kothari RU, Brott T, Broderick JP, et al. The ABCs of measuring intra-cerebral haemorrhage volumes. Stroke 1996;27(8):1304-5.

[14] Fewel ME, Thompson BG, Hoff JT. Spontaneous intracerebral haemorrhage: a review. Neurosurg Focus 2003;15(4):E1.

[15] Rathor MY, Rani MFA, Jamalludin AR, et al. Prediction of functional outcome in patients with primary intracerebral haemorrhage by clinical-computed tomographic correlations. J Res Med Sci 2012;17(11):1056-62.

[16] Al-Mufti F, Thabet AM, Singh T, et al. Clinical and radiographic predictors of intra-cerebral haemorrhage outcome. Intervent Neurol 2018;7:11836.

[17] Panchal HN, Shaw MS, Shaw DS. Intra-cerebral haemorrhage score and volume as an independent predictor of mortality in primary intra-cerebral haemorrhage patients. Indian J Surge 2015;77(Suppl 2):302-4. 
[18] Safatli DA, Gunther A, Schlattmann P, et al. Predictors of 30-day mortality in patients with primary intracerebral haemorrhage. Surg Neurol Int 2016;7(Suppl 18):S510-7.

[19] Poon MT, Fonville AF, Al-Shahi SR. Long-term prognosis after intra-cerebral haemorrhage: systematic review and meta-analysis. J Neurol Neurosurg Psychiatry 2014;85(6):660-7.

[20] Broderick JP, Brott TG, Duldner JE, et al. Volume of intra-cerebral haemorrhage. A powerful and easy-touse predictor of 30-day mortality. Stroke 1993;24(7):987-93.

[21] Flemming KD, Wijdicks EF, Li H. Can we predict poor outcome at presentation in patients with lobar haemorrhage? Cerebrovasc Dis 2001;11(3):183-9.

[22] Wada R, Aviv RI, Fox AJ, et al. CT angiography "spot sign" predicts hematoma expansion in acute intracerebral haemorrhage. Stroke 2007;38(4):1257-62.

[23] Davis SM, Broderick J, Hennerici M, et al. Hematoma growth is a determinant of mortality and poor outcome after intra-cerebral haemorrhage. Neurology 2006;66(8):1175-81.

[24] Nag C, Das K, Ghosh M, et al. Prediction of clinical outcome in acute haemorrhagic stroke from a single CT scan on admission. N Am J Med Sci 2012;4(10):463-7.

[25] Leira R, Davalos A, Silva Y, et al. Early neurologic deterioration in intra-cerebral hemorrhage: predictors and associated factors. Neurology 2004;63(3):461-7.

[26] Diringer MN, Edwards DF, Zazulia AR. Hydrocephalus: a previously unrecognized predictor of poor outcome from supratentorial intra-cerebral haemorrhage. Stroke 1998;29(7):1352-7.

[27] Ferro JM. Update on Intra-cerebral haemorrhage. J Neural 2006;253(8):985-99.

[28] Kazui S, Naritomi H, Yamamoto H, et al. Enlargement of spontaneous intra-cerebral haemorrhage, incidence and time course. Stroke 1996;7(10): 1783-7.
[29] Lee JH, Chang $\mathrm{CH}$, Jung $\mathrm{YJ}$, et al. The relationship between the direction of putaminal intra-cerebral haemorrhage and anterior cerebral artery predominance. World Neurosurg 2017;107:211-15.

[30] Becker KJ, Baxter AB, Bybee HM, et al. Extravasation of radiographic contrast is an independent is an independent predictor of death in primary intracerebral haemorrhage. Stroke 1999;30(10):2025-32.

[31] Almandoz DJE, Yoo AJ, Stone MJ, et al. Systematic characterization of the computed tomography angiography spot sign in primary intra-cerebral haemorrhage identifies patients at highest risk for hematoma expansion: the spot sign score. Stroke 2009;40(9):2994-3000.

[32] Selariu E, Zia E, Brizzi M, et al. Swirl sign in intracerebral haemorrhage: definition, prevalence, reliability and prognostic value. BMC Neurol 2012;12:109.

[33] Li Q, Zhang G, Huang YJ, et al. Blend sign on computerised tomography: novel and reliable predictor for early hematoma growth in patients with intra-cerebral haemorrhage. Stroke 2015;46(8):2119-23.

[34] Li Q, Zhang G, Xiong X, et al. Black hole sign: novel imaging marker that predicts hematoma growth in patients with intra-cerebral haemorrhage. Stroke 2016;47(7):1777-81.

[35] Sporns PB, Schwake M, Kemmling A, et al. Comparison of spot sign, blend sign and black hole sign for outcome prediction in patients with intracerebral haemorrhage. J Stroke 2017;19(3):333-9.

[36] Barras CD, Tress BM, Christensen S, et al. Density and shape as CT predictors of intra-cerebral haemorrhage growth. Stroke 2009;40(4):1325-31. 